\title{
OBSTÁCULOS E INCENTIVOS AO INTRAEMPREENDEDORISMO EM EMPRESAS INOVADORAS
}

\author{
OBSTACLES AND INCENTIVES TO INTRAPRENEURSHIP IN INNOVATIVE COMPANIES
}

\author{
Recebido em 30.12.2015. Aprovado em 04.10.2016 \\ Avaliado pelo sistema double blind review \\ DOI: http://dx.doi.org/10.12712/rpca.v10i3.708
}

\section{Adilson Caldeira}

adilson.caldeira@mackenzie.br

Universidade Presbiteriana Mackenzie (MACKENZIE), São Paulo/SP, BRASIL

\section{Alberto de Medeiros Junior}

alberto.medeiros@mackenzie.br

Universidade Presbiteriana Mackenzie (MACKENZIE), São Paulo/SP, BRASIL

\section{Resumo}

Este estudo foi realizado com o objetivo de identificar quais fatores incentivam ou dificultam o comportamento intraempreendedor por parte dos integrantes de organizações empresariais inovadoras. Após a contextualização e declaração do problema de pesquisa, apresenta-se uma revisão teórica dos aspectos relevantes pertinentes ao tema. O texto prossegue com a descrição dos procedimentos metodológicos, a apresentação e discussão dos resultados da pesquisa e as considerações finais. A investigação, de caráter qualitativo exploratório, foi efetuada por meio de entrevistas com gestores de empresas reconhecidamente inovadoras e trouxe como principais resultados indícios de que o empreendedorismo é visto como um processo passível de ser estimulado via ações gerenciais voltadas a promover condições favoráveis à sua ocorrência. Possíveis obstáculos a esse comportamento seriam a acomodação e a falta de percepção das mudanças e seus desafios.

Palavras-chave: Intraempreendedorismo. Inovação. Comportamento empreendedor.

\begin{abstract}
In order to observe and identify factors that stimulate or hinder intrapreneur behavior among members of inovative business organizations, this study begins by contextualizing and statement of research question. Following, we present a theoretical review of the relevant aspects related to the matter. The text goes on to describe the methodological procedures. The research, qualitative and exploratory, was performed by means of interviews with managers acting in companies recognized as innovative. As main results, evidence that entrepreneurship is seen as a process that can be stimulated by means of managerial actions to promote favorable conditions for their occurrence. Possible obstacles to this behavior would be the accommodation and the lack of awareness of the changes and challenges.
\end{abstract}

Keywords: Intrapreneurship. Innovation. Entrepreneurial behavior. 


\section{Introdução}

Como condicionante da sobrevivência em um ambiente turbulento e em constante evolução, uma organização é desafiada a identificar mudanças, agir e se adaptar para o aproveitamento de oportunidades. Tal comportamento se concretiza quando as pessoas que integram a organização agem de forma alinhada a essa busca pela adaptação, indo além de executar tarefas rotineiras e repetitivas para dedicar-se ao exercício de sua criatividade em busca de soluções inovativas e diferenciadas.

Tida como referência nos estudos sobre a importância da inovação para os negócios, a concepção de Schumpeter (1982) considera que a inovação fomenta a competitividade e a produtividade. Segundo essa visão, a capacidade de perceber e explorar novas oportunidades, no âmbito dos negócios e utilizar recursos disponíveis de forma inovadora, mediante aceitação de riscos calculados, é a fonte propulsora do sistema capitalista e caracteriza a essência do comportamento empreendedor. Nesse contexto, evidencia-se a estreita relação entre o comportamento empreendedor e a inovação.

Sob a ótica do desempenho corporativo, Kuczmarski (1998) atribui o sucesso das organizações inovadoras à capacidade de criar uma consciência inovadora, institucionalizando a cultura da inovação. De acordo com essa visão, uma cultura favorável ao comportamento empreendedor pode ser um agente de sucesso para uma organização, e ocorrer simultaneamente como causa e efeito de sua evolução natural, independente da vontade de quem a administra. Está ao alcance dos administradores, contudo, promover um ambiente favorável à ocorrência do comportamento empreendedor na organização.

Na década de 1980 os estudos sobreempreendedorismo passaram a incorporar o conceito de intrapreneurship, expressão criada por Pinchot III (1985), que se refere ao empreendedorismo realizado em âmbito interno e coletivo de uma organização. Dentre as primeiras visões desse fenômeno, Ross e Darab (1986) descrevem os intra-empreendedores como as pessoas que tentam trazer para a corporação a cultura do espírito de inovação. Assim sendo, presume-se que o comportamento intraempreendedor exerce uma influência na capacidade inovativa e uma organização pode obtê-lo se tiver, em sua cultura, características que o favoreçam.
Neste estudo, exploram-se características que compõem o ambiente de uma organização com potencial de influenciar, interferir, facilitar ou dificultar a ocorrência do intraempreendedorismo, que têm sido objeto de estudo tanto de pesquisadores nacionais como estrangeiros, conforme se apresenta na próxima seção, que contém a fundamentação teórica constituída para esse fim. Complementando a pesquisa, foram realizadas entrevistas com profissionais que atuam em cargos de gestão em unidades de negócio estabelecidas no Brasil de grandes empresas que atuam em âmbito internacional e se caracterizam como tipicamente inovadoras.

Assim, o estudo que ora se apresenta busca uma resposta ao seguinte problema de pesquisa: quais fatores estimulam ou constituem barreiras ao intraempreendedorismo em uma organização?

O objetivo geral é identificar quais são os fatores que estimulam ou dificultam a obtenção de comportamento intraempreendedor por parte dos integrantes de organizações empresariais reconhecidamente inovadoras.

O texto segue a seguinte estrutura: a seção 2 principia pela fundamentação teórica em que se apresentam as visões norteadoras do modelo conceitual concebido para este estudo acerca do fenômeno do empreendedorismo e suas características. $\mathrm{Na}$ seqüência, discutem-se especificamente os elementos apresentados nos estudos que focalizam ações comportamentais relativas ao intraempreendedorismo. A partir do estabelecimento dos conceitos adotados, constrói-se um quadro relativo aos aspectos que podem ser considerados favoráveis ou desfavoráveis ao comportamento intraempreendedor em uma organização. Descrevem-se, na seção 3, as opções metodológicas para a realização da pesquisa de campo, com justificativa para essas opções. Os resultados relativos ao foco deste trabalho são apresentados e analisados na seção 4. Encerrando o texto, apresentam-se as considerações finais, com as conclusões decorrentes da pesquisa realizada, uma breve exposição das suas limitações, assim como sugestões para estudos futuros. 


\section{Fundamentação teórica}

Esta seção revisa alguns princípios e conceitos presentes na literatura relacionada a empreendedorismo, de forma ampla, e em especial às abordagens específicas desse fenômeno aplicado ao comportamento inovativo e empreendedor dos indivíduos nas organizações, eventualmente caracterizado como intraempreendedorismo, buscando esclarecer a linha teórica adotada no contexto do trabalho. Destaca-se em especial como o empreendedorismo se caracteriza no interior das organizações e de que forma sua prática pode ser facilitada ou dificultada.

\section{Empreendedorismo e comportamento empreendedor}

Há, na literatura, diferentes definições para o termo empreendedorismo. Segundo Grebel, Pyka e Hanush (2003), o estudo do fenômeno do empreendedorismo se iniciou pela função econômica do empreendedor proposta por Cantillon no início do século XVIII e seguida por visões como as de Jean-Baptiste Say e Schumpeter, segundo o qual o empreendedorismo é a fonte da inovação, que funciona como um motor da competitividade e produtividade. A capacidade de perceber novas oportunidades e explorá-las, utilizando recursos disponíveis de forma inovadora mediante aceitação de riscos calculados, são as características marcantes do empreendedor (SCHUMPETER, 1982).

Talvez como evolução natural decorrente do interesse pelo tema, o estudo do fenômeno do empreendedorismo amplia seu enfoque ao apresentar visões complementares àquelas que originariamente se pautam pela ótica da Economia. É o caso de estudos comportamentais, em que o foco se concentra em características criativas e intuitivas dos empreendedores, buscando a identificação do perfil característico do empreendedor. É o caso, por exemplo, dos estudos de Weber (2004), em que se procuram identificar o sistema de valores dos empreendedores, a relação dos indivíduos com o trabalho, a necessidade de realização e a percepção do lucro como resultado do esforço pessoal.

Indicado por Filion (1999) como pioneiro do estudo do empreendedorismo sob a ótica comportamental, McClelland (1972), propõe o reconhecimento do papel do empreendedor na sociedade e suas consequências para o desenvolvimento econômico, sem, contudo, se deixar de analisar e compreender as questões relativas à motivação para que o empreendedorismo se manifeste. Propõe-se, assim, a relação entre progresso econômico e a necessidade de realização dos indivíduos, definida como o desejo de fazer algo objetivando o poder, o amor, o reconhecimento ou o lucro (ASSIS, 2005).

Segundo a concepção de Hisrich e Peters (2004, p.29), o empreendedorismo é um processo de criação de "algo novo com valor dedicando o tempo e os esforços necessários, assumindo os riscos financeiros, psíquicos e sociais correspondentes e recebendo as consequentes recompensas da satisfação e independência econômica e pessoal".

Em consonância com Hisrich e Peters (2004), Farah, Cavalcanti e Marcondes (2008) observam que a pessoa com perfil necessário para empreender é aquela capaz de desenvolver a noção do que é preciso para realizar a uma ideia, decorrente não somente de fatos como uma ruptura profissional por demissão ou aposentadoria, como também de uma oportunidade que se apresentou em sua vida. Os mesmos autores argumentam que a criatividade e a vivência pessoal possuem um peso relevante nas decisões que conduzem as empresas à diferenciação perante seus concorrentes. Observar outras empresas, aprender com os erros e os acertos dos outros, para que assim, tenha sucesso é característica essencial para quem conduz um negócio.

Longenecker, Moore e Petty (1997), por sua vez, sustentam que a essência do empreendedorismo está em três elementos: a inovação, o risco e a autonomia. Segundo os autores, a liberdade é fundamental para que os objetivos do empreendimento se concretizem. Complementarmente, Farrel (1993) argumenta que a liberdade deve estar presente em diferentes situações: liberdade para agir; tentar, arriscar, escolher, errar.

Mirshawka e Mirshawka Jr. (2003) argumentam que são características e habilidades de um empreendedor a iniciativa, a paixão pelo que faz, a criatividade na concepção de idéias e na utilização dos recursos, a aceitação de riscos e da possibilidade de fracasso, a identificação de oportunidades e as experiências prévias. Farah, Cavalcanti e Marcondes (2008) afirmam que ainda que seja difícil encontrar em uma única pessoa todas essas habilidades, é possível desenvolvê-las, e assim aprimorar o perfil tornando-o 
adequado para empreender. Além de explorar pontos fortes, podem-se reduzir pontos fracos e assim obter melhores resultados.

Compilando as características do perfil empreendedor citadas por diferentes autores, Filion (1999) considera como principais as seguintes: capacidade de inovação; liderança; tolerância à incerteza e a riscos moderados; independência; criatividade; energia; tenacidade; originalidade; otimismo; orientação para resultados; flexibilidade; habilidades para conduzir situações; necessidade de realização; autoconsciência; autoconfiança; envolvimento em longo prazo; iniciativa; capacidade de aprendizagem; habilidade na utilização de recursos; sensibilidade em relação a outras pessoas; agressividade; tendência a confiar nas pessoas e valores monetários como medida de desempenho.

Conforme se observa, os estudos descrevem o comportamento empreendedor como um conjunto de características presentes no perfil empreendedor. Por conseguinte, para a finalidade proposta neste estudo, assume-se que o empreendedorismo e o comportamento empreendedor se manifestam quando essas características são observadas nas atitudes das pessoas.

\section{Intraempreendedorismo e cultura organizacional intraempreendedora}

Considerando as diferentes definições de empreendedorismo e as características comumente atribuídas ao empreendedor, é possível identificar a relação direta com um comportamento que caracteriza aspectos como mudança, inovação, aprendizagem e criatividade (SOUZA; LOPEZ JR.; 2005; MURPHY; LIAO; WELSCH, 2006).

Pautados por essa visão comportamental do empreendedorismo, Souza e Lopez Jr. (2005) observam que se trata de um fenômeno dinâmico, que não se restringe ao padrão de comportamento de apenas um indivíduo, compreendendo um processo que envolve um conjunto de fatores. Abordagens como as de Hisrich e Peters (2004) e Baron e Shane (2007), consideram que o empreendedorismo pode ser visto como um processo. Para Hisrich e Peters (2004), trata-se de um processo em que se cria algo diferente e com valor. Baron e Shane (2007) concordam, afirmando que esse processo se inicia com a percepção de oportunidades para criar novos produtos ou serviços.

Essa visão processual do intraempreendedorismo é compartilhada por Dornelas (2009, p. 38), para quem esse fenômeno representa "um processo pelo qual um indivíduo ou grupo de indivíduos, associados a uma organização existente, criam uma nova organização ou instigam a renovação ou inovação dentro da organização existente”.

Uma organização é constituída por um conjunto de indivíduos que compartilham objetivos e valores. Hofstede (1991), afirma que a cultura de uma organização determina a identidade do grupo de pessoas que a compõe do mesmo modo que a personalidade determina a identidade de cada indivíduo. Assim sendo, o empreendedorismo, que é definido como um conjunto de características presentes no perfil de um indivíduo, pode ser transposto para a cultura de uma organização. Com base nesse princípio, Pinchot III (1985) introduziu, nos estudos sobre empreendedorismo, o termo intrapreneurship, (literalmente traduzido para o português como intraempreendedorismo) conferindo a essa expressão o significado de práticas empreendedoras realizadas em âmbito interno e coletivo de uma organização, incluindo atividades relacionadas a funções administrativas do negócio.

Segundo Pinchot III (1989), da mesma forma que um indivíduo pode realizar seu perfil empreendedor iniciando um negócio de sua propriedade, há espaço para que o empreendedorismo esteja presente em uma carreira em uma organização já existente. Comparando as vantagens que um intraempreendedor encontra em relação ao empreendedor convencional, Pinchot III (1989) indica quatro aspectos estruturais favoráveis ao intraempreendedorismo em uma corporação: o marketing, a base tecnológica, os recursos para investimento e a estrutura de pessoas. O primeiro desses aspectos, relativo a marketing, favorece o intraempreendedorismo à medida que o marketing aliado ao atendimento e à distribuição eficiente dos produtos constitui uma condição que fará o projeto do intraempreendedor frutificar rapidamente, usando os canais corporativos. No que se refere ao segundo aspecto, que é a base tecnológica, uma empresa pode manter uma estrutura destinada à pesquisa e desenvolvimento. $O$ terceiro aspecto refere-se à disponibilidade de recursos financeiros 
para investimento em projetos que ainda não são cobertos pelos capitalistas de risco. O quarto aspecto está relacionado à estrutura de pessoas já existente em uma corporação, que pode participar a assim favorecer a realização do projeto.

Stevenson e Jarillo (1990, p.23) estabelecem um paralelo entre o empreendedorismo individual e o intraempreendedorismo. Segundo os autores, o intraempreendedorismo representa "um processo pelo qual, indivíduos - tanto dentro como fora de organizações - perseguem oportunidades a despeito dos recursos que controlam". O intraempreendedor é o gerente ou o executivo que age como se estivesse empreendendo seu próprio negócio, dentro dos limites de uma organização já estabelecida.

Segundo Hashimoto (2006, p. 14), atividades intraempreendedoras são aquelas que indicam “(...) qualquer forma de proposição de mudanças e melhorias na organização ou dentro dos limites da rede direta de relacionamentos da organização que, de alguma forma, se traduz em aumento de valor para o cliente ou para o acionista".

De acordo com Filion (2004), intraempreendedor é a pessoa que desenvolve uma visão que orienta a organização sobre o que deve ser feito. As ações intraempreendedoras, portanto, caracterizam-se como aquelas que proporcionam o desenvolvimento e a implementação de novas visões.

\section{Barreiras e estímulos ao Comportamento Empreendedor nas Organizações}

De acordo com estudos sobre o fenômeno do intraempreendedorismo como um processo organizacional, existem meios que favorecem e meios que dificultam a sua ocorrência. Toftoy e Chatterjee (2004), por exemplo, entendem que o processo de desenvolvimento do intraempreendedorismo se inicia em uma organização em pequenos passos, e à medida que as pessoas vão ficando mais confortáveis com a ideia, desenvolvem confiança nos resultados, e gradualmente a corporação se torna empreendedora. Com isso, a tendência é de que novos projetos evoluirão em processos mais autônomos, proporcionando que aflorem as habilidades inovadoras dos indivíduos que integram a organização. $\mathrm{O}$ caminho passa pelo desenvolvimento de visão, estabelecimento da missão, evoluindo por meio de passos como a articulação, a formação de equipes, a elaboração de planos de ação e, consequentemente, o reconhecimento da necessidade de um clima inovador, de forma a se fazer o intraempreendedorismo acontecer. Trata-se, portanto, de um processo de desenvolvimento de uma cultura organizacional alinhada com os princípios comportamentais do empreendedorismo.

Desde a proposta germinal de Pinchot III (1985), que chamou a atenção para o fenômeno do intraempreendedorismo, há estudos relativos ao empreendedorismo como um comportamento esperado dos funcionários de uma organização. Ross e Darab (1986), por exemplo, consideram que intraempreendedores são pessoas que trazem o espírito de inovação para a cultura organizacional. Partindo dessa premissa, realizaram estudos nos quais constataram que apesar da tendência de burocratização das organizações, várias delas adotaram novas culturas e introduziram atividades para minimizar vínculos estruturais e encorajar a inovação.

Smircich (1983) afirma que a cultura organizacional pode ser enfocada segundo duas categorias. $\mathrm{Na}$ primeira, ela é considerada como um instrumento que pode ser utilizado para aplicar estratégias e direcionar o rumo tomado pela empresa. Segundo essa perspectiva, considera-se que o desempenho da organização é produto dos valores e crenças compartilhados por seus membros e pelo compromisso que eles assumem. $\mathrm{Na}$ segunda categoria, a cultura organizacional é interpretada como uma metáfora, de forma que o sentido dos eventos organizacionais são fenômenos coletivos fundamentados na construção da realidade, em que percepções, conhecimentos e juízos sobre os eventos interagem para conferir significado às manifestações de cultura.

Em consonância com os objetivos deste estudo, direciona-se o foco da análise das características de uma cultura favorável ao comportamento intraempreendedor de uma organização com base na primeira categoria, ou seja, partindo-se da concepção da cultura organizacional como instrumento que pode ser utilizado para aplicar estratégias. Assim sendo, analisa-se, segundo essa premissa, as propostas encontradas na literatura que abordam processos destinados à construção de uma cultura organizacional empreendedora.

Ross e Darab (1986) prescrevem três princípios básicos para que as organizações pratiquem uma gestão 
intraempreendedora: primeiro, adotar fundamentos da administração profissional, segundo, adotar um estilo de comportamento que transcende a burocracia e encoraja inovação, e terceiro, estimular os intraempreendedores.

Pinchot III e Pellman (2004) sustentam que o intraempreendedor pode ser considerado um indivíduo que combina a visão de um gerente geral de um negócio que ainda não existe, naturalmente orientado para a ação. Trata-se de um gestor com uma visão diferente da que se encontra em um gerente comum ou em um empreendedor convencional. Pinchot III (1989) apresenta os principais diferenciais entre essas três categorias de gestores em quatro dimensões: motivos principais, ações, habilidades e relacionamento com outros. A Figura 1 sumariza essas distinções.

Considerando essas características, Pinchot III e Pellman (2004) entendem que, para fomentar o potencial do intraempreendedorismo, as grandes empresas devem atuar com a agilidade das pequenas, de forma a favorecer o poder inovador e a iniciativa dos intraempreendedores. Estes não são, necessariamente, inventores de novos produtos ou serviços, e sim contribuintes do desempenho organizacional por meio de novas idéias e projetos que se transformem em realidades lucrativas.

Alencar (1995) e Barbieri, Álvarez e Cajazeira (2009) alertam para a influência do ambiente de trabalho sobre o potencial de inovação. Essa visão, associada às características do comportamento intraempreendedor propostas por Pinchot III (1989) e Pinchot III e Pellman (2004), permite considerar que um ambiente corporativo proporciona estímulos à ocorrência do intraempreendedorismo quando valoriza aspectos como a liberdade, acesso aos recursos da corporação, comprometimento com metas, condições para a automotivação, recompensas e reconhecimento. Além disso, segundo Pinchot III e Pellman (2004), o intraempreendedor necessita de tempo para construir e testar seus modelos mentais. Ele pode aprender e desenvolver capacidade de visualizar os passos que serão necessários para o trajeto que vai da idéia à efetiva realização do projeto. É importante, pois, que a organização inclua em sua cultura a tolerância a riscos, erros e falhas.

Figura 1. Características de gerentes, empreendedores e intraempreendedores.

\begin{tabular}{|c|c|c|c|}
\hline & $\begin{array}{c}\text { Gerentes } \\
\text { Tradicionais }\end{array}$ & Empreendedores tradicionais & Intraempreendedores \\
\hline $\begin{array}{l}\text { Motivos } \\
\text { principais }\end{array}$ & $\begin{array}{l}\text { Quer promoções e } \\
\text { outras recompensas } \\
\text { corporativas } \\
\text { tradicionais. } \\
\text { Motivado pelo poder. }\end{array}$ & $\begin{array}{l}\text { Quer liberdade. } \\
\text { Orientado para metas, } \\
\text { autoconfiante e automotivado. }\end{array}$ & $\begin{array}{l}\text { Quer liberdade e acesso aos recursos } \\
\text { da corporação. Orientado para metas } \\
\text { e automotivado, mas também reage às } \\
\text { recompensas e ao reconhecimento da } \\
\text { corporação. }\end{array}$ \\
\hline Ação & $\begin{array}{l}\text { Delega a ação. } \\
\text { Supervisão e relatórios } \\
\text { levam a maior parte da } \\
\text { energia. }\end{array}$ & $\begin{array}{l}\text { Põe a mão na massa. Pode } \\
\text { aborrecer os empregados, } \\
\text { fazendo de repente o trabalho } \\
\text { deles. }\end{array}$ & $\begin{array}{l}\text { Põe a mão na massa. Pode saber } \\
\text { como delegar, mas quando necessário } \\
\text { faz o que deve ser feito. }\end{array}$ \\
\hline Habilidades & $\begin{array}{l}\text { Gerência profissional. } \\
\text { Com freqüência } \\
\text { formado em escola } \\
\text { de administração. } \\
\text { Ferramentas analíticas } \\
\text { abstratas, administração } \\
\text { de pessoas e habilidades } \\
\text { políticas. }\end{array}$ & $\begin{array}{l}\text { Conhece intimamente o negócio. } \\
\text { Mais agudez para negócios do } \\
\text { que habilidade gerencial ou } \\
\text { política. Frequentemente com } \\
\text { formação técnica, se em um } \\
\text { negócio técnico. Pode ter sido } \\
\text { responsável por lucros e perdas } \\
\text { na antiga corporação. }\end{array}$ & $\begin{array}{l}\text { Muito semelhante ao empreendedor, } \\
\text { mas a situação exige maior capacidade } \\
\text { para prosperar dentro da organização. } \\
\text { Necessita de ajuda neste aspecto. }\end{array}$ \\
\hline $\begin{array}{l}\text { Relacionamento } \\
\text { com os outros }\end{array}$ & $\begin{array}{l}\text { Hierarquia como } \\
\text { relacionamento básico. }\end{array}$ & $\begin{array}{l}\text { Transações e acordos como } \\
\text { relacionamento básico. }\end{array}$ & Transações dentro da hierarquia. \\
\hline
\end{tabular}

Fonte: Pinchot III, 1989, p. 45-47. 
A construção de um ambiente favorável passa, portanto, pelo estabelecimento de políticas alinhadas a essas condições. Scherer e Carlomagno (2009) argumentam que é primordial que a organização tenha sua Visão, Missão e os Valores claros e definidos como balizadores para as ações. Esses elementos devem definir quem são os clientes, tanto externos quanto internos, como se relacionar com eles e também com fornecedores, sociedade e demais stakeholders envolvidos. O conhecimento dos valores, da missão e da visão na organização contribui para o processo criativo, alinhando os esforços em busca de ideias alternativas em termos de produtos, processos ou serviços se todos os colaboradores compreendem a razão de existência de sua organização (SCHERER; CARLOMAGNO, 2009).

Alencar (1995), Bonache (2000) e Barbieri, Álvarez e Cajazeira (2009), consideram que o comportamento inovativo e a criatividade são favorecidos pelo investimento em treinamento para o desenvolvimento pessoal e profissional, atualização das habilidades e aquisição de novos conhecimentos. Além do incentivo à busca por novas ideias, o treinamento também pode contribuir para a divulgação das crenças, valores e filosofia da organização.

Vasconcellos e Hemsley (2003) consideram a influência das formas organizacionais (estruturas) quando se lida com mudanças e atividades incertas e inovadoras. Nessas condições, a comunicação horizontal e diagonal deve fluir de acordo com as condições necessárias para que a criatividade não seja inibida por barreiras estruturais, uma vez que as interações entre as pessoas e a troca de informações proporcionam insights para o processo criativo (ROBINSON; SCHROEDER, 2005).

A importância atribuída à comunicação para interação em busca de criatividade e inovação é compartilhada por autores como Koen et al. (2002) e Nagle, Westerski e Iglesias (2011), que defendem a utilização de processos formais para geração de ideias, por meio de técnicas como sessões com grupos e brainstorming, dentre outros.

A atuação do líder é indicada como condição de estímulo ou de barreira para que o comportamento inovativo e empreendedor ocorra na organização por autores como Masood et al. (2006), Jong e Hartog (2007) e Arruda, Rossi e Savaget (2009). Segundo essa perspectiva, os liderados são influenciados pelas atitudes e valores de seus líderes. Caso interpretem que a inovação e a iniciativa empreendedora é valorizada tendem a se motivar para adotá-las como referência comportamental.

No que se refere a condições motivacionais que podem estimular ou bloquear o comportamento empreendedor, Pinchot III e Pellman (2004) argumentam que o intraempreendedor é guiado por motivos diferentes dos gerentes tradicionais de uma organização. Enquanto a motivação destes últimos pode se limitar a perspectivas de promoções e outras recompensas tradicionais, o intraempreendedor quer liberdade e acesso aos recursos da corporação, é orientado para metas e automotivado, mas também reage às recompensas e ao reconhecimento da corporação.

Por fim, conforme afirmam Nelson e Vangundy (2007), um aspecto muito importante para que se obtenha suficiente motivação para a geração de ideias e envolvimento com o negocio é a estrutura do sistema de recompensa. Cada organização estabelece o seu sistema próprio de reconhecimento ou de recompensa de acordo com suas características culturais, sociais e econômicas.

\section{Aspectos metodológicos}

O relato de pesquisa aqui apresentado faz parte de um estudo de caráter qualitativo com propósito exploratório que se pautou pelo objetivo de identificar fatores que estimulam ou dificultam a obtenção de comportamento intraempreendedor por parte dos integrantes de organizações empresariais reconhecidamente inovadoras.

Como estratégia de coleta de dados realizaram-se entrevistas semi-estruturadas com gestores afinizados com o tema. O número de entrevistas foi determinado com base na recomendação de Johnson (2002), para quem o número ideal é o quanto o pesquisador ache suficiente para descobrir o que busca, inclusive retornando à abordagem de alguns dos informantes que aparentemente detenham maior conhecimento sobre um assunto específico de uma determinada categoria. 
Dessa forma, foram escolhidos os sujeitos considerados os mais preparados para fornecer as informações desejadas. Foram selecionados cinco profissionais que atuam em cargos de gestão em quatro empresas internacionais presentes com divisões que atuam no Brasil, reconhecidas por serem inovadoras, figurando como objeto de estudos em diversas publicações acadêmicas direcionadas ao estudo do tema Inovação, líderes em rankings internacionais de patentes depositadas e relacionadas dentre as empresas mais inovadoras, de acordo com levantamento "Best Innovator", realizado pela consultoria A.T. Kearney, em parceria com a revista Época Negócios (ÉPOCA NEGÓCIOS, 2013).

De comum acordo com os participantes, optou-se por preservar em sigilo os nomes dos respondentes e as empresas que representam. Com esse critério, as referências autores de afirmações cujos trechos foram extraídos das entrevistas são apresentadas como E1 (entrevistado No. 1), E2 (entrevistado No. 2), e assim sucessivamente, até E5 (entrevistado No. 5). Para se ter uma ideia das áreas e níveis hierarquicos de atuação dos entreevsitados, relaciona-se, na Figura 2, seus postos e o mercado em que suas empresas atuam.

Figura 2. Participantes da pesquisa

\begin{tabular}{|c|c|c|}
\hline Entrevistado & $\begin{array}{l}\text { Ramo da } \\
\text { empresa }\end{array}$ & Cargo \\
\hline E1 & $\begin{array}{l}\text { Indústria } \\
\text { atuando em } \\
\text { diversos } \\
\text { setores } \\
\end{array}$ & $\begin{array}{l}\text { Gerente de } \\
\text { Marketing e Vendas } \\
\text { de Divisão }\end{array}$ \\
\hline E2 & $\begin{array}{l}\text { Tecnologia } \\
\text { de } \\
\text { Informação }\end{array}$ & $\begin{array}{l}\text { Diretor de } \\
\text { Tecnologia e } \\
\text { Inovação }\end{array}$ \\
\hline E3 & $\begin{array}{l}\text { Tecnologia } \\
\text { de } \\
\text { Informação }\end{array}$ & $\begin{array}{l}\text { Gerente de } \\
\text { Desenvolvimento } \\
\text { de Negócios }\end{array}$ \\
\hline E4 & $\begin{array}{l}\text { Indústria } \\
\text { atuando em } \\
\text { diversos } \\
\text { setores }\end{array}$ & $\begin{array}{l}\text { Diretor de } \\
\text { Marketing }\end{array}$ \\
\hline E5 & $\begin{array}{l}\text { Indústria } \\
\text { de Eletro- } \\
\text { Eletrônicos }\end{array}$ & $\begin{array}{l}\text { VP } \\
\text { Desenvolvimento } \\
\text { de Produtos e } \\
\text { Inovação }\end{array}$ \\
\hline
\end{tabular}

Fonte: Elaborado pelos autores.
Tendo como principal direcionador o problema de pesquisa e o objetivo estabelecidos para o trabalho, elaborou-se um roteiro com o propósito de conferir à entrevista um caráter semi-estruturado. Seguindo a sugestão de Flick (2004, p.118), para quem "O elemento central dessa forma de entrevista é o convite periódico à apresentação de narrativas de situações", elaborou-se um roteiro composto de onze questões abertas inspiradas no modelo teórico inicial.

As entrevistas, que tivefram, em média, a duração de 60 minutos cada, foram realizadas no ambiente de trabalho dos entrevistados e gravadas com seu consentimento. As gravações foram transcritas na íntegra, sendo que, com a preocupação de manter o contexto original do momento da entrevista, as transcrições contêm em detalhes as perguntas feitas pelo entrevistador e as respostas dos entrevistados.

A análise dos dados foi realizada com base na técnica de análise de conteúdo proposta por Bardin (2006). Conforme recomenda a autora, principiou-se pela fase de organização dos dados, operacionalização e sistematização das ideias iniciais, na qual se procedeu ao preparo do material, mediante uma pré-análise, de maneira a conduzir a um esquema preciso para um plano de análise. Dessa forma, foi realizada uma leitura prévia das transcrições das entrevistas.

Após esta etapa, efetuou-se a codificação, pela transformação sistemática dos dados brutos em unidades de registro. Para efeito da codificação e categorização, as entrevistas foram lidas por completo, de forma a tornar possível a compreensão do sentido do todo e também para decidir quais trechos mereceram destaque em função dos padrões e temas que emergiram.

A análise das cinco entrevistas possibilitou a codificação de 772 unidades de registro consideradas como referências para a observação dos aspectos relevantes citados pelos entrevistados. A seguir, as unidades de registro foram reunidas por similaridade em unidades de significado, o que facilitou a identificação de padrões dentre as informações obtidas, uma vez que o agrupamento de levou à redução da análise a nove unidades de significado.

Posteriormente, desenvolveu-se a classificação de elementos em categorias temáticas pelo critério semântico. Bardin (2006) afirma que a categorização 
compreende a definição de classes que reúnem um conteúdo ao qual se atribui um título genérico, possibilitando o agrupamento de elementos que possuem caracteres comuns. Assim, estabeleceram-se quatro categorias por meio da análise realizada: a categoria 1 (C1) refere-se à importância atribuída à cultura organizacional como fonte de estímulo ao comportamento intraempreendedor; a categoria 2 (C2) corresponde a políticas e valores considerados como estímulo ao comportamento empreendedor; categoria 3 (C3) envolve aspectos estruturais que constituem estímulos ou barreiras ao comportamento empreendedor; e a categoria 4 (C4) compreende aspectos motivacionais para o comportamento intraempreendedor.

O agrupamento das nove Unidades de Significado nessas quatro categorias é apresentado na Figura 3.

Figura 3. Categorias de análise

\begin{tabular}{ll}
\hline Categorias & Unidades de Significado \\
\hline C 1: Influência da cultura organizacional no & US 6: cultura empreendedora \\
comportamento intraempreendedor & US 8: cultura de inovação \\
\hline
\end{tabular}

C 2: Políticas e valores que estimulam o comportamento empreendedor
US 2: diretrizes estratégicas (visão, missão, valores)

US 4: conscientização e treinamento sobre as diretrizes
C 3: Influência de aspectos estruturais no comportamento empreendedor
US 1: meios de comunicação

US 7: estrutura de liderança
C 4: Aspectos motivacionais para o comportamento intraempreendedor
US 3: liberdade para a criatividade e inovação

US 5: Reconhecimento e recompensa

Fonte: Elaborado pelos autores.

Uma vez esclarecidos os procedimentos para coleta e análise dos dados, apresenta-se, a seguir, a discussão dos resultados obtidos.

\section{Apresentação e discussão dos resultados da pesquisa}

Neste tópico apresentam-se os resultados obtidos mediante a classificação por categoria de análise. Cada categoria é apresentada em um subitem, em que se confrontam as visões encontradas na literatura com as dos entrevistados, utilizando-se excertos das declarações obtidas. Nesses excertos foram mantidos os desvios linguísticos que eventualmente ocorreram nos depoimentos, de forma a preservar o contextualizo das respostas.

\section{Influência da cultura organizacional no comportamento intraempreendedor}

De um modo geral, os entrevistados reconhecem que o intraempreendedorismo é um comportamento benéfico à organização e representa um processo que deve ser estimulado. Essa visão é convergente com as propostas apresentadas por Hisrich e Peters (2004), Baron e Shane (2007) e Dornelas (2009), segundo as quais o comportamento empreendedor das pessoas pode ser obtido por meio da gestão desse processo, como meio 
para que os indivíduos que participam da organização proporcionem inovação. São exemplos dessa visão afirmações como as seguintes:

No ambiente em que a gente vive, uma inovação pode trazer resultados temporário, de curta duração, É preciso criar um processo, com atividade, entradas e saídas, responsáveis e métricas que geram alguma coisa. Cada organização tem o seu processo, que depende de coisas formais e também informais, como fatores culturais, como a propensão ao risco que aquele grupo vai ter, etc (E1).

Inovação para nós são 3 pilares fundamentais: espírito empreendedor, inclusão e colaboração e governança dos processos de inovação (E2).

A inovação permeia também os funcionários. Então necessariamente as patentes não vêm somente do laboratório de pesquisa, vêm também da interação e colaboração entre os funcionários (E3).

No começo, quando a empresa estava sendo moldada, forjada, aquilo era intuitivo $[\ldots]$ as pessoas não fizeram estudos disso que eu falei, mas [...] começou a criar essa reputação, começou a aumentar as vendas, o faturamento... Tá bom, agora eu preciso criar um sistema, eu preciso profissionalizar, não tenho que esperar um colega trazer uma nova ideia, $\mathrm{e}$ se ele trouxer... Agora vamos tentar forçar, estimular, criar mecanismos [...] (E4)

O processo de inovação significa a forma de fazer a inovação. As decisões devem considerar que o comportamento inovador da empresa decorre de seus colaboradores, não apenas dos pesquisadores e cientistas (E5).

Ainda no que se refere à categoria 1 , quanto à cultura organizacional para o comportamento empreendedor, Ross e Darab (1986), encontraram evidências empíricas de que apesar da tendência de burocratização das organizações, várias delas adotaram novas culturas e introduziram atividades para encorajar a inovação. Segundo os entrevistados esse fenômeno é reconhecido pelas equipes gestoras das organizações em que atuam. Evidenciam-se, dentre os depoimentos obtidos com esse sentido, os seguintes:
É fundamental a mentalidade da empresa estar alinhada com a inovação. Não precisa estar escrito na visão, no sonho da empresa que ela quer ser inovadora, mas ela tem que estar sonhando em fazer algo grande. Algo que se você não quiser fazer algo diferente, você nunca vai atingir (E1).

Então, acho que é dever de toda a empresa, a partir do presidente, fomentar uma cultura de que as pessoas possam pensar. No pensar e ter ideias a gente é bom (E2).

No começo, os primeiros líderes foram criando cultura organizacional, que a gente chama de personalidade da empresa, ou seja, muito favorável pra inovação, muito favorável para novas ideias serem dadas, investidas, com paciência, aquilo vira um novo negócio, uma nova divisão [...] (E4).

Como terceiro aspecto considerado na Categoria 1, as entrevistas revelam que os gestores que atuam em organizações que deliberadamente buscam promover a inovação por meio das atitudes de seus participantes percebem algumas características comuns ao comportamento intraempreendedor. Nota-se que os entrevistados apresentam opinião que se alinha à visão de Pinchot III (1989) e Pinchot III e Pellman (2004) sobre possíveis barreiras ao intraempreendedorismo e à inovação se não for reconhecida a necessidade de tempo para construir e testar modelos mentais e aprender, e, sobretudo, a tolerância a riscos, erros e falhas. Esse alinhamento se revela com maior clareza nas seguintes afirmações:

Uma forma de fazer a inovação surgir é investir tempo no amadurecimento da ideia, e o líder deve incentivar seus liderados a usar parte de seu tempo para esse amadurecimento. Outra forma de facilitar a inovação é a questão da tolerância ao erro. [...] Uma boa parte do que você for fazer de inovação vai dar errado, e aí, amanhã você acertar, no ano que vem você gera outra patente... Primeiro é isso. Depois, esse conhecimento, aquilo que não deu certo deve ser compartilhado. [...] Por " $n$ " mecanismos: encontros, o jornalzinho, banco de dados, ele registra aquela ideia e tenta estimular: algum de vocês aí têm uma ideia para aplicação desse produto, por que eu não tenho, né, e aí, essa informação foi disseminada pela organização. Tem que ter paciência, porque não é no dia seguinte que ele passou a ideia e alguém achou (E1). 
Se o meu colaborador tem medo de errar porque então será punido, como eu posso cobrar dele que inove e tome a iniciativa na hora de resolver um problema? Nossas regaras são claras quanto a não punir. Eu posso estar sempre cobrando, mas não punindo. (E3)

Na cultura empreendedora, é fundamental assumir riscos e tolerar erros. A postura das lideranças deve orientar as pessoas para assumir riscos, não riscos estúpidos, sem embasamento, sem a mínima segurança, sem conhecimento, porque isso se chama aventura. [...] mas a ideia de assumir riscos é muito importante, senão a empresa fica andando de lado, com pequeno crescimento lateral, se a economia vai mal você se conforma, se resigna... Você tem que ter no comportamento das pessoas essa característica de assumir riscos (E4).

\section{Políticas e valores que estimulam o comportamento empreendedor}

Alguns dos entrevistados indicam como um dos aspectos que podem estimular o comportamento intraempreendedor e inovativo a definição desse compromisso nas diretrizes estratégicas. Essa ideia converge com a literatura em menções como a de Scherer e Carlomagno (2009), que argumentam sobre o papel da Visão, Missão e os Valores claramente definidos, em termos de como balizadores para as ações. Nota-se a presença dessa visão em nos seguintes trechos:

Uma empresa, ela não nasceu desse jeito, ela pode se transformar numa organização inovadora, mas tem que levar em conta [...] uma visão muito clara e comunicada para os funcionários. (E2).

É importante direcionar os objetivos de inovação para o futuro, em produtos $\mathrm{e}$ em áreas que se encaixam no escopo da empresa e que com os quais as pessoas se envolvam e percebam como podem ser úteis aos consumidores e à sociedade. $\mathrm{Ou}$ seja, a cultura empreendedora é facilitada quando se tem um propósito (E4).

Conforme ilustram os trechos reproduzidos a seguir, também classificados como integrantes da Categoria 2, alguns dos entrevistados mencionam como um aspecto que pode estimular o comportamento empreendedor o investimento em treinamento para o desenvolvimento pessoal e profissional, atualização das habilidades e aquisição de novos conhecimentos. Esses aspectos são mencionados na literatura por fontes como Alencar (1995), Bonache (2000) e Barbieri, Álvarez e Cajazeira (2009), segundo os quais, além do incentivo à busca por novas ideias, o treinamento também pode contribuir para a divulgação das crenças, valores e filosofia da organização.

\begin{abstract}
A gente precisa de novo cair sempre no tema educação, a gente precisa de técnicos, engenheiros, enfim, cientistas, para executar os projetos. (E2).
\end{abstract}

O treinamento também é uma coisa muito importante. [...] A 3M, como a GE e muitas outras, elas investem muito na capacitação das pessoas para que elas possam continuar perpetuando aquele mecanismo de respeitar o funcionário, da gente conseguir vender, contagiar o funcionário com uma visão de crescimento, de futuro (E4).

\section{Influência de aspectos estruturais no comportamento empreendedor}

Conforme se apresenta na fundamentação teórica construída para este estudo, os canais de comunicação presentes na estrutura organizacional são aspectos que podem influenciar o comportamento empreendedor. A esse respeito, há menções dos entrevistados sobre estímulos proporcionados pela comunicação quando se lida com mudanças e atividades incertas e inovadoras, conforme afirmam autores como Robinson e Schroeder (2005), Koen et al. (2002) e Nagle, Westerski e Iglesias (2011). Nesse sentido, os entrevistados declaram:

[...] é uma empresa que vem constantemente se recriando, renovando, em termos de produtos, de posicionamento no mercado [...] anos atrás não fazia o que faz hoje, obviamente, $[. .$.$] continua mudando, e um$ dos motivos é isso, esse investimento [...] em pesquisa e inovação, desenvolvimento, criatividade, olhando sempre o futuro. [...] os cientistas reúnem, estão sempre trocando ideias [...] a gente faz uma colaboração, uma interação [...] o próprio uso da mídia, da rede social interna, que nós temos, de colaboração, e-mail, chats, 
blogs, tem uma série de mecanismos, instrumentos que permitem que os funcionários possam colaborar, trocar ideia, e a gente é muito incentivado a isso, a fazer esse tipo de inovação interna, e isso acaba colaborando com essas ideias que a gente trabalha para o futuro (E3).

Também é importante que o ambiente não seja hostil, em que as pessoas se sintam encorajadas em propor ideias e juntamente com suas lideranças encarem os erros como aprendizagem. Por isso, é igualmente importante que o ambiente seja de troca de experiências, com canais de interação para que as pessoas divulguem suas descobertas e troquem ideias (E4).

Outro aspecto a considerar como estrutural e que pode proporcionar estímulos ou obstáculos ao comportamento intraempreendedor, também analisados na Categoria 3, refere-se à forma pela qual se processa a lideranças. Em relação à influência da liderança no comportamento inovativo e empreendedor da organização, as entrevistas revelam, nos trechos reproduzidos a seguir, visões comuns às de autores como Masood et al. (2006), Jong e Hartog (2007) e Arruda, Rossi e Savaget (2009). Assim como essas fontes bibliográficas, os entrevistados entendem que os liderados são influenciados pelas atitudes e valores de seus líderes, de forma que se a inovação e a iniciativa empreendedora são valorizadas pela liderança, tendem a se motivar para adotá-las como referência comportamental.

[...] O ser humano precisa muito de modelos. A igreja nos fornece modelos, nossa família costuma nos dar alguns modelos de comportamento, etc.,[...] É importantíssimo ter uma liderança preparada [...] as pessoas em geral ou são mais sistemáticas ou mais criativas, com variações de perfil, um dessas aí vai virar chefe. Às vezes é o criativo, outras o sistemático que vira chefe. A coisa só vai funcionar bem se você tiver gente criativa e gente sistemática trabalhando junto. E é fácil perder a mão e o sistemático achar que o criativo dá muito boa ideia mas não trabalha e o criativo que o outro é um tapado, que só fica fazendo o que mandam. Esse tipo de conflito, se você não tiver uma liderança preparada para lidar com isso, provavelmente você não vai ser bem sucedido. (E1)
[...] inovação é uma missão de todo mundo. Acho que inovação nasce como ideia. Ideia, pensamento todo mundo tem. Então acho que é dever de toda a empresa, a partir do presidente, fomentar uma cultura de que as pessoas possam pensar. Muitas vezes ideias criativas que poderiam trazer um resultado bom nem são apresentadas porque o sujeito não vê no seu líder o entusiasmo para patrocinar essa ideia (E2).

[...] Então, escolha a pessoa líder [...] aquele que tem autonomia, aquele que tem iniciativa, empreendedorismo, fala o objetivo para ele, [...] e deixa ele trabalhar do jeito dele [...] Ele que vai receber uma boa ideia, e aí apoiar, investir, alocar recursos, porque sempre a gente está falando em priorizações na empresa [...]. $\mathrm{O}$ líder deve incentivar o funcionário que apresenta uma boa ideia a usar parte de seu tempo em desenvolvê-la, em vez de se concentrar exclusivamente em sua rotina de trabalho, no projeto que ele vem desenvolvendo (E4).

[...] uma coisa que consideramos que é importante para nós chegarmos lá é atribuir poder aos líderes com visão mais ampla, com uma visão ampla dos resultados da gestão [...] se as pessoas não tiverem modelos a seguir, vão se limitar a fazer o básico (E5).

\section{Aspectos motivacionais para 0 comportamento intraempreendedor}

Nessa categoria, consideram-se as condições motivacionais características do intraempreendedor que, segundo Pinchot III e Pellman (2004), quer liberdade e acesso aos recursos da corporação, é orientado para metas e automotivado, mas também reage às recompensas e ao reconhecimento da corporação. Sobre liberdade e orientação para metas, as entrevistas revelam que:

\footnotetext{
O nosso desafio, para criar um ambiente criativo na organização, é permitir que as pessoas tenham liberdade individual para criar. A busca pela inovação é uma fonte inesgotável de motivação, pois Toda pessoa afetivamente saudável gostaria de participar de algo importante na vida [...] Quando você propõe fazer algo diferente, algo grande, em geral isso é uma fonte de motivação, mais duradoura que o dinheiro, normalmente. (E1).
} 
Uma empresa inovadora tem que ser uma boa empresa para se trabalhar. Você tem um ambiente que te inspira confiança, você se sente reconhecido, você sente que tem recursos disponíveis [...] Quando a pessoa sai da zona de conforto, vai além da descrição de cargo e depois não acontece nada, ela não escuta o feedback da ideia dela, se a ideia vai para frente ela não sabe de nada que aconteceu, se dá certo ela não vê nada, nem um muito obrigado. Péssimo, né, então, todo um programa em que se pretende estimular o empreendedorismo precisa, no mínimo, garantir que toda a ideia receba uma resposta. [...] empresa inovadora tem que ter uma métrica que orienta todo o esforço e os investimentos da companhia. No nosso caso, a gente precisa que $40 \%$ das vendas venham de produtos novos, produtos lançados nos últimos 5 anos. (E4).

No que se refere aos aspectos relativos a reconhecimento e recompensa, também integrantes da categoria 4, a opinião de alguns entrevistados, refletida nos trechos a seguir reproduzidos, revela que o comportamento empreendedor na organização pode ser favorecido ou obstruído dependendo de como os esforços individuais são reconhecidos. Essa opinião coincide com o que propõem Nelson e Vangundy (2007), que, além de evidenciar a influência desse aspecto na motivação para a geração de ideias e envolvimento com o negocio, argumentam que cada organização estabelece o seu sistema próprio de reconhecimento ou de recompensa de acordo com suas características culturais, sociais e econômicas.

[...] o reconhecimento é indispensável se você quer criar uma cultura de inovação. $\mathrm{Eu}$ falo em reconhecimento, não em recompensa, que é outra coisa. O reconhecimento mexe com coisas muito íntimas nossas [...] Isso tende a ser muito mais duradouro em termos de motivação do que dinheiro. Então, o reconhecimento é indispensável (E1).

[...] o reconhecimento é ponto importante para estimular a inovação, mas não tem uma forma única, exclusiva de fazer o reconhecimento, porque depende muito da cultura da organização. [...] a gente tem uma forma de reconhecimento específica, e é muito das pessoas apresentarem suas ideias serem reconhecidas pela alta liderança, recebe seu troféu, tem oportunidade de compartilhar sua ideia com outros países, com outros profissionais, essa visibilidade da sua ideia. Isso impacta na sua carreira. Você vai eventualmente pegar uma carreira internacional, vai ser promovido, etc. Outras empresas preferem [...] você vai participar do lucro, vai ganhar o $15^{\circ}$. Salário, Isso também é válido, depende da empresa. Cada empresa tem uma forma. O importante é reconhecer a atitude. Você pede um comportamento inovador, criativo, aí quando a pessoa faz isso tem que trazer impacto no crescimento da pessoa (E4).

Observa-se, assim, que os indivíduos tendem a se engajar a um comportamento organizacional que favorece o empreendedorismo e a inovação quando vê seus esforços reconhecidos. Não há, contudo, uma receita única proposta para que se proporcionem tais condições, uma vez que é fundamental a consideração de características específicas de cada organização quanto à cultura organizacional imperante.

\section{Considerações finais}

A proposta central deste estudo foi identificar e analisar quais aspectos estimulam ou impõem barreiras ao comportamento intraempreendedor em uma organização. Assumiu-se como pressuposto que o intraempreendedorismo é um comportamento desejável para organizações que buscam melhorias para o desempenho futuro. Caso pretendam promover um ambiente favorável ao comportamento intraempreendedor, devem conhecer os aspectos que proporcionam estímulos a esse comportamento, de forma a fomentá-los, bem como os que de alguma forma constituem barreiras à sua ocorrência e devem ser evitados.

Optou-se pela realização de uma pesquisa qualitativa de caráter exploratório, principiando pela construção de um referencial teórico e aplicando as descobertas obtidas nas fontes bibliográficas consultadas a um roteiro que direcionou as entrevistas efetuadas com gestores experientes no tema em estudo.

A seguir, procura-se estabelecer uma síntese sobre as principais descobertas para cada uma das interações observadas no presente estudo, a partir da reflexão sobre os aspectos constantes na literatura consultada 
e nos depoimentos dos entrevistados. Consideram-se, para esse fim, alguns aspectos implícitos, pois ainda que alguns autores se restrinjam a indicar agentes de estímulo ao comportamento intraempreendedor, pode-se inferir que a ausência desses agentes representa um meio de constituir barreiras. De forma análoga, se um aspecto representa barreira ao comportamento intraempreendedor, sua eliminação poderia se constituir em um estímulo.

A pesquisa revela o reconhecimento do empreendedorismo como um processo, passível de ser administrado, por meio do qual os indivíduos criam uma nova organização ou instigam a renovação ou inovação dentro da organização existente. Assim sendo, pode-se considerar como estímulo ao comportamento intraempreendedor a ação gerencial voltada a promover condições favoráveis à sua ocorrência. Uma possível barreira a esse comportamento seria a acomodação e falta de percepção de mudanças por parte dos gestores.

Em contraponto ao estímulo potencial decorrente da adoção de nova cultura e introdução de atividades para minimizar vínculos estruturais, encorajando a liberdade de ação como condição para a inovação, poderia se constituir em barreira ao intraempreendedorismo o excesso de burocratização, refletida em estruturas organizacionais excessivamente rígidas em termos de hierarquia, autonomia e responsabilidades.

Reconhece-se como estímulos $\mathrm{aO}$ intraempreendedorismo a concessão do tempo necessário para o desenvolvimento de novos modelos mentais e a aprendizagem, com tolerância a riscos, erros e falhas. Assim sendo, a adoção de sistemas punitivos rigorosos, intolerantes ao erro e o imediatismo na cobrança dos resultados de iniciativas inovadoras pode se constituir em barreira.

Diretrizes organizacionais estratégicas como a visão, a missão e os valores adotados possuem um potencial de estimular o comportamento empreendedor. A comunicação dessas diretrizes aos indivíduos que integram a organização e sua conscientização para a necessidade de alinhamento de sua atuação a elas pode se constituir em um elemento facilitador para o comportamento intraempreendedor. Por isso, a ausência de meios de comunicação e de treinamento podem se constituir em barreiras.
A colaboração e compartilhamento de conhecimento entre as pessoas possuem o potencial de fomentar o comportamento inovativo. Novas ideias podem ser aperfeiçoadas quando ocorre interação entre os autores e seus pares. Para isso, devem existir canais de comunicação direta para essa interação, sem vínculos a processos de comunicação excessivamente formais, que poderiam se constituir em barreiras.

O comportamento da organização é influenciado pelas ações de liderança, uma vez que os indivíduos seguem modelos de comportamento e procuram moldar o seu ao que percebem que é valorizado por seus líderes. Identificar e atribuir funções de liderança a pessoas com perfil empreendedor pode ser um estímulo, enquanto a presença de líderes excessivamente autoritários e centralizadores pode ser uma barreira ao comportamento intraempreendedor.

A orientação para metas e resultados pode ser considerada um aspecto motivacional do comportamento intraempreendedor, pois proporciona o comprometimento com os objetivos organizacionais. Promovendo esse comprometimento, a organização pode conferir liberdade de atuação aos indivíduos desde que estes cumpram as metas estabelecidas, o que alavanca a automotivação. O mesmo ocorre quando o cumprimento das metas é reconhecido, seja por meio de recompensa material ou de oportunidade para auto-realização. Por conseguinte, a ausência de comprometimento com metas e a falta de feedback e reconhecimento são considerados potenciais barreiras ao intraempreendedorismo.

Face a tais indícios encontrados na literatura e confirmados ou complementados com os dados obtidos na pesquisa de campo, considera-se que o objetivo estabelecido para este estudo foi realizado, ainda que se reconheça a possibilidade de um aprofundamento maior que possibilite compreender aspectos que carecem de esclarecimento.

Por mais cuidado que se tenha ao elaborar uma pesquisa, é comum que ela possua limitações. Este estudo não é diferente. Especialmente pelo fato de ser um estudo exploratório, o objetivo não é conclusivo e as descobertas não podem ser consideradas como aplicáveis a quaisquer situações. No entanto, exatamente pelo seu caráter exploratório, ele abre possibilidades para novas pesquisas. A partir dos achados aqui descritos é possível imaginar inúmeras 
investigações adicionais, que possibilitem constatar a existência de aspectos que facilitam e outros que dificultam a prática do intraempreendedorismo nas organizações, contribuindo para que elas possam desenvolver meios que lhes permitam a gestão desse fenômeno de forma a alavancar ainda mais seu desempenho.

\section{Referências}

ALENCAR, E. M. L. S. Desenvolvendo a criatividade nas organizações: o desafio da inovação. RAE - Revista de Administração de Empresas, v. 35, n.6, p. 6-11, 1995.

ANDRADE, C. C. J.; RIELLI, M. E. Emoções: dimensão diferencial para a transformação das organizações, 2000. Disponível em: <http:/ /www. ligare.psc.br/leituras_interno.asp? ID_Leitura=14>. Acesso em: 12 de Junho de 2014.

ARRUDA, C.; ROSSI, A.; SAVAGET, P. Oportunidades e desafios de inovar. Revista da Fundação Dom Cabral, v. 2, n. 8, p. 37-43, 2009.

ASSIS, S. Empreendedorismo e empreendedor. In: SOUZA, E.C.L. Diferentes visões à luz da cultura. Brasília: SESI/DN, 2005, unidade 1, p. 1329.

BARBIERI, J. C.; ÁLVARES, A. C. T.; CAJAZEIRAS, J. E. R. Gestão de ideias para inovação contínua. Porto Alegre: Bookman, 2009.

BARDIN, L. Análise de Conteúdo. 4. ed. Lisboa: Edições 70, 2006.

BARON, R. A.; SHANE, S. A.

Empreendedorismo: uma visão do processo. São Paulo: Thomson Learning, 2007.

BONACHE, J. The Internacional Transfer of na Idea Suggestion System: against radical relativism in internacional human resource management.

International Studies of Management and Organization, v. 29, n. 4, p. 24-44, 2000.

DOLABELA, F. Oficina do empreendedor: a metodologia de ensino que ajuda a transformar conhecimento em riqueza. Rio de Janeiro: Sextante, 2008.

DORNELAS, J. C. A. Empreendedorismo Corporativo. Rio de Janeiro: Elsevier Brasil, 2009.

ÉPOCA NEGÓCIOS. As empresas que são exemplo de inovação. Disponível em: <http:/ / epocanegocios.globo.com/Inspiracao/Empresa/ noticia/2013/11/empresas-que-sao-exemplo-deinovacao.html>. Acesso em 19 de Dezembro de 2013.

FARAH, Osvaldo Elias; CAVALCANTI, Marly; MARCONDES, Luciana Passos (Orgs.). Empreendedorismo estratégico. São Paulo: Cengage Learning, 2008.

FARREL, L. C. Entrepreneurship: fundamentos das organizações empreendedoras. São Paulo: Atlas, 1993.

FILION, L. J. Diferenças entre sistemas gerenciais de empreendedores e operadores de pequenos negócios. Revista de Administração de Empresas, 39(4), 6-20, 1999.

FILION, L. J. Entendendo os intra-empreendedores como visionistas. Revista de negócios, v.9, n.2, p. 65-79, 2004.

FLICK, U. Uma introdução à pesquisa qualitativa. 2a. Ed. Porto Alegre: Bookman, 2004.

GREBEL, T.; PYKA, A.; HANUSCH, H. An evolutionary approach to the theory of entrepreneurship. Industry and Innovation, v. 10, n. 4, p. 493-514, dec. 2003.

HASHIMOTO, M. Espírito empreendedor nas organizações: aumentando a competitividade

através do intra-empreendedorismo. São Paulo: Saraiva, 2006.

HOFSTEDE, G.H. Cultures and organizations: software of the mind. New York: McGraw-Hill, 1991.

KOEN, P. et al. Fuzzy front end: effective methods, tools and techniques. In: BELLIVEAU, 
P.; GRIFFEN, A.; SORERMEYER, S. (Ed.). The PDMA toolbook for new product development. New York: John Wiley and Sons, 2002.

HISRICH, R., PETERS, M. Empreendedorismo (5a. ed.). Porto Alegre: Bookman, 2004.

JONG, J.; HARTOG, D. How leaders influence employees' innovative behaviour. European Journal of Innovation Management. v.10, n.1, p.41- 64, 2007.

JOHNSON, J. M. In-depth interviewing. In: HOLSTEIN, J. A.; GUBRIUM, J. F. (Eds.) Handbook of interview research: context $\&$ method. Thousand Oaks: Sage Publications, 2002, p. 103-119.

KUCZMARSKI, T. D. Por uma consciência inovadora. São Paulo: Revista HSM Management, $\mathrm{n}^{\circ}$ 6, ano 1, p.62-68, 1998.

LONGENECKER, J. G.; MOORE, C. W.; PETTY, J. W. Administração de pequenas empresas. São

Paulo: Pearson Education do Brasil, 1997.

LOWEN, A. A espiritualidade do corpo.

Bioenergética para a beleza e a harmonia. São Paulo: Cultrix, 1995.

MASOOD, S.A.; DANI, S.S.; BURNS, N.D.; BACKHOUSE, C.J. Transformational leadership and organizational culture: the situational strength perspective. Journal of Engineering Manufacture, London, v.220, n.6, p.941-949, Feb. 2006.

McCLELLAND, D.C. A sociedade competitiva: realização e progresso social. Rio de Janeiro: Expressão e Cultura, 1972.

MIRSHAWKA, V.; MIRSHAWKA JÚNIOR, V.. Gestão criativa: aprendendo com os mais bemsucedidos empreendedores do mundo. São Paulo, 2003.

MURPHY, P. J.; LIAO, J.; WELSCH, H.P. A conceptual history of entrepreneurial thought. Journal of Management History, v. 12, n. 1, p. 1235, 2006.

NAGLE, T.; WESTERSKI, A.; IGLESIAS, C. A.
The road from community ideas to organizational innovation: a life cycle survey of idea management systems. International Journal Web Based Communities, Olney, v. 7, n. 4, 2011.

NELSON, B. VANGUNDY, L. 1001 maneiras de premiar seus colaboradores. Rio de Janeiro: Sextante, 2007.

PINCHOT III, G. Intrapreneuring: You Don't Have to Leave the Corporation to Become an Entrepreneur, New York: Harper and Row, 1985.

PINCHOT III, G. Intrapreneuring: porque você não precisa deixar a empresa para ser um empreendedor. São Paulo: Harbra Ltda., 1989.

PINCHOT III, G.; PELLMAN, R. Intraempreendedorismo na prática. Um guia de inovação nos negócios. Rio de Janeiro: Campus, 2004.

ROBINSON, A. G.; SCHROEDER, D. M. Ideas are free: how the idea revolution is liberating people and transforming organizations. São Francisco: Berret-Koehler Publishers, Inc., 2005.

ROSS, J. E.; DARAB, U. Who Is an Intrapreneur? Personnel New York: 1986. v. 63, n. 12; p. 45.

ROY, R. Intracorporate Entrepreneurs

Management Decision. London: 1987. v. 25, n. 2; p. 12.

SCHERER, F. O.; CARLOMAGNO, M. S. Gestão as inovação na prática: como aplicar conceitos e ferramentas para alavancar a inovação. São Paulo: Atlas, 2009.

SCHUMPETER, J. A. Teoria do desenvolvimento econômico: uma investigação sobre capital, crédito, juro e o ciclo econômico. Tradução de Maria Silvia Possas. São Paulo: Abril Cultural, 1982.

SMIRCICH, Linda. Concepts of culture and organizational analysis. Administrative Science Quartely, New York, v.28, n.3, p.339-358, Sept. 1983.

SOUZA, E.C.L.; LOPEZ JUNIOR, G. S. Atitude empreendedora em proprietários-gerentes de 
pequenas empresas: construção de um instrumento de medida - IMAE. READ, 48 ed., v. 11, p. x-x, nov./dez. 2005.

STEVENSON, H. H.; JARILLO, J. C. A paradigm of entrepreneurship: entrepreneurial management. Strategic Management Journal, n. 11, p. 17-27, 1990.

TOFTOY, C.; CHATTERJEE, J. The Intrapreneurial Revolution: now is the time for action, ICSB 50thWorld Conference, 2004.

VASCONCELLOS, E.; HEMSLEY, J. R. Estrutura das organizações: estruturas tradicionais, estruturas para inovação, estrutura matricial. 4. ed. rev. São Paulo: Pioneira, 2003.

WEBER, M. A ética protestante e o espírito do capitalismo. São Paulo: Companhia das Letras, 2004. 